\title{
Young people practicing martial arts and their perception of success
}

\author{
Cynarski W.J. ${ }^{\text {ABDE }}$, Pawelec P. ${ }^{2 \mathrm{CDE}}$, Yu J.-H. ${ }^{3 \mathrm{~B}}$, Slopecki J. ${ }^{4 \mathrm{~B}}$, Bielec G. ${ }^{5 \mathrm{~B}}$, Kubala K. ${ }^{6 \mathrm{~B}}$ \\ ${ }^{1}$ Department of Physical Education, University of Rzeszów, Poland \\ ${ }^{2}$ International Martial Arts and Combat Sports Scientific Society (IMACSSS), Poland \\ ${ }^{3}$ Department of Health and Physical Education, Glenville State College, United States of America \\ ${ }^{4}$ International Martial Arts and Combat Sports Scientific Society (IMACSSS), Poland \\ ${ }^{5}$ Department of Physical Education, University of Rzeszów, Poland \\ ${ }^{6}$ Department of Physical Education, University of Rzeszów, Poland
}

Authors' Contribution: A - Study design; B - Data collection; C - Statistical analysis; D - Manuscript Preparation; E-Funds Collection

\begin{abstract}
Purpose: $\quad$ The scientific framework for this study is the Humanistic Theory of Martial Arts that provides the specific language and definitions for Combat Sports/Martial Arts manifestations.

The main aim was to describe the "perception of success" in groups in age 15-17, 11,11\% girls and 88,89\% boys involved in martial arts training. Participants $(n=63)$ consisted of young martial artists from Poland and the United States.

Material: $\quad$ The instrument used for data collection was the Perception of Success Questionnaire (POSQ) (translated into Polish); Statistical analysis consisted of calculating the Spearman rank correlation for each pair of subgroups being analyzed a Coefficient of variation for comparison between the values of measurement.

Results: $\quad$ 1) A weak correlation between the type of cultivated fighting style and the perceptions of success (Spearman rank correlation $=$,35); 2) A moderate relationship between the US participants versus the Polish participants, and the perceptions of success (Spearman rank =,69); and 3) A weak relationship between sex (as a gender) and the perceptions of success in the martial arts and combat sports (Spearman rank $=, 34$ ).

Conclusions: This study concludes that the form or style of cultivated martial art or combat sport being practiced did not have a significant impact on the perception of success expressed by children and young people engaged in it.

Keywords: martial arts, combat sports, success attribution, task orientation, pedagogy.
\end{abstract}

\section{Introduction}

The scientific framework for this study is the Humanistic Theory of Martial Arts and the holistic Anthropology of Martial Arts [1, 2]. This theory provides the language for definitions and understanding all types of CS\&MA - Combat Sports and Martial Arts [3]. According to the theory, a person practicing any of these disciplines is treated holistically, encompassing his or her needs and motivations, values and aspirations, body and spirit.

Perceptions of success, along with task/goal orientation, is an important issue in the psychology of sports and modern coaching, as well as for pedagogy and physical education $[4,5]$. This approach stems from the psychology of education [6], built on conceptions of goals, tasks, and success; as described by Nicholls [7] in his achievement goal theory. According to Nicholls, there are two types of goal orientation, namely learning orientation and performance orientation. Both types are components or manifestations of the motivational processes affecting learning.

A number of researchers have focused on the philosophical basis of martial arts as the key to explaining their impact on the perceptions of success and the aspirations of those who participate in these disciplines $[8,9,10]$. Various socio-cultural characteristics of the martial arts, which influence the perceptions of

(C) Cynarski W.J., Pawelec P., Yu J.-H., Slopecki J., Bielec G., Kubala K., 2018

doi:10.15561/18189172.2018.0502 participants, leading to the internalization of special ethos are frequently identified and discussed in the literature $[11,12,13]$.

This study poses two research problems, the first of which is to determine the effect of the style or form of martial art or combat sport being practiced on the perceptions of success of those youths who practice it. The research question associated with this is, "Is there a relationship between the perceptions of success expressed by the respondents in the study and the form of martial art they practice?" The second research problem concerns the determination of whether differences exist between the perceptions of success among groups of children and young people practicing martial arts in Poland versus in the United States. Hence, the research question for this second problem is, "Are there any differences in the results by country of origin and residence, and of what they can (possibly) result?" In response to the above research questions, this study poses the following hypotheses: 1) There is no statistically significant correlation between the perceptions of success in martial arts and combat sports and the type or form of martial art and combat sport being practiced, and 2) Any differences in the statements of the respondents from different countries may be attributed primarily to cultural differences.

The authors want to analyse the relationship of adolescents' participation of success according the martial arts discipline and country. The first hypothesis was that no statistically significant dependence would be 
found between the perceptions of success and the form of cultivated martial art or combat sport being practiced. The second hypothesis was that the differences in the statements of the respondents from two different cultural backgrounds in the study, the United States and Poland, in terms of their perceptions of success.

Aim

The problem and aim of this study is to explain the "perception of success" among groups of children and young people practicing martial arts. What correlations exist between the answers of respondents and types of martial arts they practice? Is there a relationship between the perceptions of success expressed by the respondents and the specific martial arts discipline? Do differences exist in these results based on the country of origin and residence of the participants, and if so, what are these differences?

\section{Material and Methods}

Participants. The number of respondents who had volunteered to participate and were randomly selcted was $\mathrm{N}=63$ persons ( 28 from the US and 35 from Poland). The ratio of boys to girls in the study corresponds to the proportion of boys to girls actively engaged in the martial arts group-training in both countries. The data are presented in Table 1.

Table 1. Demographic characteristics of respondents by sex

\begin{tabular}{lllllll}
\hline $\begin{array}{l}\text { Sex/ } \\
\text { country }\end{array}$ & \multicolumn{2}{l}{$\begin{array}{l}\text { United } \\
\text { States }\end{array}$} & \multicolumn{2}{l}{ Poland } & \multicolumn{2}{c}{ Alltogether } \\
\hline Sex & $\mathrm{N}$ & $\%$ & $\mathrm{~N}$ & $\%$ & $\mathrm{~N}$ & $\%$ \\
Girls & 2 & 3,17 & 5 & 7,94 & 7 & 11,11 \\
Boys & 26 & 41,27 & 30 & 47,62 & 56 & 88,89 \\
\hline
\end{tabular}

Source: own research

The statistics contained in the Table 2 are calculated on the basis of data on age diversity found among survey respondents.

Table 2. Average age of respondents by sex (gender)

\begin{tabular}{llll}
\hline Sex/country & $\begin{array}{l}\text { United } \\
\text { States }\end{array}$ & Poland & Alltogether \\
\hline Sex & & & \\
Girls & 16,5 & 17 & 16,75 \\
Boys & 15,12 & 15,3 & 15,21 \\
\hline
\end{tabular}

Source: own research

The average age of the respondents (boys and girls) from the two countries varied. The highest average among those practicing martial arts was that of the Polish girls, followed by the American girls, the Polish boys and the Americans boys.

Research Design.
This project was conducted under the auspices of the International Martial Arts and Combat Sports Scientific Society (IMACSSS), specifically its Division of Sociology and Anthropology, along with its Division of Pedagogy. The research was solicited and sponsored by the IMACSSS under the heading 1A/2011: "Social determinants of participation in schools and clubs of martial arts", and approved by the Ethical Committee of Idokan Poland Association.

The tool used for this study was the Perception of Success Questionnaire (POSQ) [13], adopted for children. The data were collected in Poland and the USA, among children and young people practicing jujutsu, karate, taekwondo, kung fu, and mixed martial arts (MMA). The study was conducted between October 2015 and January 2016 in the United States (New York) and in Poland (Rzeszow, Skarzysko-Kamienna, Strzyzow, and Warsaw). It was translated into Polish and explained to the respondents in gyms/training places.

Statistical Analysis.

The data was analysed using the Statistica software (Version 13; StatSoft, Palo Alto, CA, USA). Statistical analysis consisted of calculating the Spearman rank correlation for each pair of subgroups being analyzed a Coefficient of variation for comparison between the values of measurement.

\section{Results}

This questionnaire contained twelve affirmative statements, to which the participants indicated their responses of a scale of potential acceptance or rejection of the statement, ie, their degree of agreement or disagreement. These sentences express the following attitudes: 1) "I beat other people", 2) "I am clearly superior", 3) "I am the best", 4) "I work hard", 5) "I show clear personal improvement", 6) "I outperform my opponents", 7) "I reach a goal", 8) "I overcome difficulties", 9) "I reach personal goals", 10) "I win", 11) "I show other people I am the best", and 12) "I perform to the best of my ability" [13]. Of couurse, the POSQ was translated into Polish.

The subjects rated their relationship to the above sentences based on a five-option scale from A (Strongly agree), B (Agee), C (Neutral), D (Disagree), to E (Strongly disagree). Individual responses are assigned corresponding rank (5-1). It should be noted that the questions 4, 5, 7-9, and 12 were classified as Task orientation, while 1-3, 6, 10, and 11 were classified as Ego orientation [13]. The results were used in the analysis, measuring the acceptance of these attitudes and possibly occurring correlations. It is assumed that those participanting in Poland have a European traditional (Christian) cultural background, while those respondents in the United States have an American cultural background.

The first hypothesis was examined separately for task orientation and ego orientation. Moreover, in order to thoroughly ascertain the presence or absence of dependence, the statistical analysis made statements and calculations ranks due to types of martial arts classified 
as involving either greater or lesser degree of contact. For each of these classifications, the following statistics were calculated: 1) the arithmetic mean, 2) the standard deviation, and 3) the strength of relationships between variables, based on the Spearman rank correlation. The results are presented in Table 3.

The martial arts categories included in this study were chow gar kung-fu, modern jujitsu, jujitsu goshinryu, jujitsu styleless, jujitsu idokan, karate idokan, karate isshin-ryu, and iaido; the combat sports categories included mixed martial arts (MMA), kickboxing, judo, and taekwondo. The term limited contact sports was used to include all those forms traditionally described as 'martial arts'.

The data contained in Table 3 indicate a variation in the responses of children and youth training in combat sports versus in martial arts with regard to the subject of success (in terms of purpose and self-development). Respondents representing the martial arts to agree, that success depends on achieving the specific objectives. This outcome was similar to the responses other than "definitely". These participants indicated that they were neutral concerning the claims that their form of practice is equally important orientation for self-development. In the case of respondents practicing martial arts, speifically those varieties involving less contact, these results are presented in the same manner. The standard deviation in individual cases indicate a lack of diversity in the responses given.

The results of the Spearman rank correlation yielded a statistic of ,35, indicating a weak correlation between the type of cultivated fighting style and the perceptions of success on the part of participants. Moreover, because the calculated ratio, 2.83 , is higher than, 05 , the hypothesis that there is no statistically significant dependence of the perception of success in the martial arts upon the type of cultivated martial art or combat sport being practicing must be accepted.

Again, in testing of the second hypothesis, responses to the categories task orientation and ego orientation were separated and calculations were ranked with regard to cultural area. The results are shown in Table 4.

The data contained in Table 4 indicate a lack of diversity in the responses of participants in sports and of martial arts, regardless of their respective cultural areas. Respondents from the American cultural area agree, that success depends on achieving the specific objectives and were neutral to claim that self-development is an equally important orientation. In the case of participants representing the European cultural area, the results from their responses were analogous. Furthermore, the standard deviation calculated for the responses given indicate no significant differences.

Coefficient of variation (given in percent) ego orientation and task orientation are between forty and sixty percent $(42.6 ; 44.2 ; 52.6 ; 54.8)$, and thus there is a great diversity of statistical data.

The result of the Spearman rank correlation was ,69, indicating a moderate correlation between the respondent's being from the American versus the European cultural area and that respondent's perception of success. Because the calculated ratio, 2.22, is higher than, 05 , the hypothesis predicting the absence of any statistically significant dependence of the perceptions of success in the martial arts upon the participant's cultural background or country of origin must be accepted.

Also of interesting also are the results of analyzing the perceptions of success based on the sex of (as a gender) the respondents. The data obtained are shown in Table 5.

The data contained in Table 5 indicate a lack of diversity among the responses given by either the girls or the boys in relation to the subjects of achieving objectives and self-development. The girls agreed to the proposition, that success depends on achieving the specified targets, but gave a neutral response to the idea that self-evelopment is an equally important orientation. In a similar fashion, the boys agreed with the statement that success depends on achieving the goal, but expressed a neutral attitude towards the idea that success is associated with selfdevelopment. The standard deviations were calculated

Table 3. Perceptions of success and type of cultivated martial arts practiced

\begin{tabular}{lllllll}
\hline \multirow{2}{*}{ Orientation/practicing } & \multicolumn{3}{l}{ Martial arts } & \multicolumn{4}{c}{ Combat sports } \\
& $\bar{X}$ & Sd & $\mathbf{v}$ & $\bar{X}$ & Sd & V \\
\hline Task orientation & 1,61 & 0,91 & $56,5 \%$ & 1,72 & 0,83 & $48,2 \%$ \\
Ego orientation & 2,61 & 1,19 & $45,6 \%$ & 2,63 & 1,2 & $45,6 \%$ \\
\hline
\end{tabular}

Source: own research. The level of significance is $p<0.05$.

Table 4. Perceptions of success and cultural area

\begin{tabular}{lllllll}
\hline \multirow{2}{*}{ Orientation/area } & \multicolumn{3}{l}{ American cultural area } & \multicolumn{4}{l}{ European cultural area } \\
& $\bar{X}$ & Sd & v & $\bar{X}$ & Sd & V \\
\hline Task orientation & 1,81 & 0,8 & $44,2 \%$ & 1,57 & 0,86 & $54,8 \%$ \\
Ego orientation & 2,58 & 1,1 & $42,6 \%$ & 2,49 & 1,31 & $52,6 \%$ \\
\hline
\end{tabular}

Source: own research. The level of significance is $p<0.05$. 
Table 5. Perceptions of success and sex

\begin{tabular}{|c|c|c|c|c|c|c|}
\hline \multirow[b]{2}{*}{ Orientation/sex } & \multicolumn{2}{|l|}{ Girls } & \multicolumn{3}{|c|}{ Boys } & \multirow[b]{2}{*}{ v } \\
\hline & $\overline{\mathrm{X}}$ & Sd & $\mathbf{v}$ & $\overline{\mathrm{X}}$ & Sd & \\
\hline Task orientation & 1,7 & 0,88 & $51,8 \%$ & 1,73 & 0,84 & $48,5 \%$ \\
\hline Ego orientation & 2,86 & 1,36 & $47,5 \%$ & 2,6 & 1,18 & $45,4 \%$ \\
\hline
\end{tabular}

Source: own research. The level of significance is $p<0.05$.

and indicate that no significant differences exist in the responses given by boys versus girls.

Coefficient of variation (given in percent) ego orientation and task orientation are between forty and sixty percent $(45.4 ; 47.5 ; 48.5 ; 51.8)$, and thus there is a great diversity of statistical data.

The result of the Spearman rank correlation was .34, indicating that only a weak relationship between sex and the perception of success. Because the calculated ratio, 1.98 , is higher than ,05, the hypothesis that the differences in the statements of the respondents from two different cultural backgrounds in the study, the United States and Poland, in terms of their perceptions of success must be accepted.

\section{Discussion}

The tool, Perceptions of Success Questionnaire (POSQ), is used frequently in research that is similar to this study and involves young people who practice and play sports $[14,15,16]$. However, martial arts have their own specific characteristics, setting them apart from other sports with respect to the POSQ. The type of practice itself is not an important determinant of either task orientation or success attribution.

In one study, young CS\&MA participants $\left(\mathrm{n}_{1}=477, M\right.$ age $=14$ yr., $S D=2.13$ ) who practiced judo, aikido, kick-/ Thai boxing or karate were assessed in terms of their aggressiveness, goal orientations, psychosocial behaviour, and social background, using their responses, as well as those of their parents $(\mathrm{n} 2=307)$. The authors of the study concluded that "differences exist in the characteristics and social background of participants depending on the type of MA\&CS being practiced. The fact that differences in these mediating factors can be identified indicates that in future research these and possible other mediating factors should be considered when trying to determine socialpsychological outcomes of MA\&CS." [16]. However, in the results show above we found only a weak correlation with the type of MA \&CS.

The results (shown above) are generally compatible with similar research, conducted in order to assess what affects young people practicing martial arts [17, 18, 19]. However, the works varies in terms of the relationships determined between goal orientation and each of the following factors: 1) the perceived motivational climate in the participant's environment, 2) the perception of ability and attributions of success in sport, 3) the enjoyment of sports practice, 4) the commitment and dedication to learning, and 5) the anxiety experienced in relation to errors and stressful situations. "Ego orientation correlated with ego perceived motivational climate in parents, trainer and partners; with a higher perception of ability; with normative ability and deceit as way to achieve success in sport, and with boredom. Task orientation correlated with motivation-effort in order to achieve success, with sports practice enjoyment, anxiety over stressful situations and with a lower learning commitment and dedication" [19].

In the M. Lochbaum's group, "The ego goal was practically meaningless to small in meaningfulness related to all of correlate categories (...) these small in meaningfulness relations were consistent" $[20,21]$. Also, in the Polish-American research the task orientation was pointed predominatingly.

Harwood recognized that the measures described or referred to above may not yield accurate or meaningful information on an athlete's motivational responses in the contexts of competition and practice. In this researcher's study, the contextual sensitivity of the TEOSQ and the POSQ was examined empirically using a sample of 179 high-level team and individual athletes. The results of data analysis involving repeated measures ANOVAs, supported by follow-up paired t-tests, illustrated how performers' goal orientations for competition differed significantly from their overall sport goal orientations. "The findings are discussed with reference to the implications for practitioners and the development of appropriate contextual assessments of achievement goals at nomothetic and idiographic levels" [22].

In another research study utilizing the same data set, a two-stage cluster analysis of the POSQ scores revealed a three-cluster solution when subjected to a multivariate analysis of variance, thereby indicating significant differences among cluster groups in imagery use. Athletes in the Cluster 3 group (higher task/higher ego) used significantly more imagery, regardless of its function than did athletes in Cluster 1 (lower task/moderate ego) or those in Cluster 2 (moderate task/lower ego). "These findings are discussed with reference to the role of achievement motivation in influencing young athletes' behavioural investments in mental strategies" [23].

Other studies of athletes and their orientation to task provide little in the way of conclusive results. For instance, Roberts, Treasure, and Kavussanu examined the relationship between dispositional achievement goal orientations and satisfaction and beliefs about success in sports. In this research, 333 student participants were administered the Perception of Success Questionnaire (POSQ), the Beliefs about Success, and the Satisfaction/ 
Interest/ Boredom Questionnaires. Among these participants, task and ego goal orientations were found to be orthogonal. "Following an extreme group split of the task and ego subscales of the POSQ, results of a $2 \times 2$ (High/Low Ego; High/Low Task) multivariate analysis of variance revealed a significant interaction effect between task and ego orientation. Specifically, participants high in ego and low in task orientation believed effort to be less a cause of success while high task/low ego-oriented individuals were the least likely to attribute success to external factors" [24].

In a similar study, albeit one focusing on recreation activity in general, the purpose was actually to develop and examine the reliability and validity of the Perceptions of Success Questionnaire for Exercise (POSQ-E), and to link goal orientation to self-reported physical activity patterns and perceptions. In this case, the sample consisted of 569 recreation centre participants who utilized the facility 3.77 days a week $(\mathrm{SD}=1.94)$ and were active for an average of 70.18 minutes $(\mathrm{SD}=33.3)$ per session. "Sixty-three percent of respondents $(n=358)$ self-reported meeting adult guidelines for regular exercise (150 minutes per week). Using a single-item ladder, participants were assigned across the five stages of exercise readiness respectively: precontemplation (6.8\%); contemplation (4.9\%); preparation (26.2\%); action (23.8\%); and maintenance (38.3\%). Task scores were shown to increase across the stages of change while ego scores decreased slightly. An extreme median split of the goal orientation scores yielded a sub-sample of 235 participants with 76 $(32.3 \%)$ in the high task/high ego, $49(20.9 \%)$ in the high task/low ego, 47 (20\%) in the high ego/low task, and 63 $(26.8 \%)$ in the low ego/ low task group. The POSQ-E was shown to have good internal reliability, factor validity and convergent validity. Convergent validity linking the trans-theoretical model and self-reported physical activity behaviour with goal orientation theory may provide a new direction for applied research in exercise behaviour" [25].

\section{Conclusions}

The present study, reported here, adds to the knowledge based of the literature in the field by indicating that the form or style of cultivated martial art or combat sport being practiced does not have a significant impact on the perception of success expressed by children and young people engaged in it, whether boys or girls. Furthermore, acording to these results, there are no differences in responses, conditioned by the cultural background or country of origin of the respondent.

\section{Acknowledgements}

None.

\section{Conflict of interests}

The authors declare that there is no conflict of interest.

\section{References}

1. Cynarski WJ. Martial Arts Phenomenon - Research and Multidisciplinary Interpretation. Rzeszow: Rzeszow University Press; 2012.

2. Zeng HZ, Cynarski WJ, Xie L. Martial Arts Anthropology, Participants' Motivation and Behaviours. Martial Arts in Chanshu: Participants' Motivation, Practice Times and Health Behaviours. Saarbrücken: Lambert Academic Publishing; 2013.

3. Cynarski WJ, Skowron J. An analysis of the conceptual language used for the general theory of martial arts -Japanese, Polish and English terminology. Ido Movement for Culture. Journal of Martial Arts Anthropology. 2014; 14 (3): 49-66.

4. Ames C. Classrooms: goals, structures, and student motivation. Journal of Educational Psychology. 1992; 84(3): $261-71$.

5. Endresen I, Olweus D. Participation in power sports and antisocial involvement in preadolescent and adolescent boys. Journal of Child Psychology and Psychiatry. 2005;46(5): 468-78.

6. Elliot A. The Hierarchical Model of Approach-Avoidance Motivation. Motivation and Emotion. 2016;30(2): 111-6.

7. Nicholls J. Conceptions of ability and achievement motivation. In Ames R, Ames C, editors. Research on motivation in education. San Diego: Academic Press; 1984. p. 39-73.

8. Bäck A, Kim D. Towards a Western philosophy of the Eastern martial arts. Journal of the Philosophy of Sport. 1979; 5:1928.

9. Cynarski WJ. General reflections about the philosophy of martial arts. Ido Movement for Culture. Journal of Martial
Arts Anthropology. 2013;13(3): 1-6.

10.Cynarski WJ, Lee-Barron J. Philosophies of martial arts and their pedagogical consequences. Ido Movement for Culture. Journal of Martial Arts Anthropology. 2014;14(1): 11-9.

11.Obodynski K, Cynarski WJ. Social and Philosophical Determinants of the Lifestyle of a Contemporary Student of Martial Arts. In: Hodan B, editor. Proceedings from the Czech-Slovak-Polish Symposium Télesná vychova, sport a rekreace v procesu současné globalizace 2005 Feb 17-18 [Physical Education, Sport and Recreation in the Process of Contemporary Globalization, 2005 Feb 17-18]. Brno. Olomouc: Univerzita Palackeho v Olomouc; 2005. P. 271-81.

12.Zeng HZ, Xie L, Cynarski WJ. Young Martial Arts Athletes' Motivation and their Health-Related Behaviours. Research Quarterly for Exercise and Sport. 2013;84(1): A78-9.

13.Roberts G, Treasure D, Balague G. Achievement goals in sport: The development and validation of the Perception of Success Questionnaire. Journal of Sports Sciences. 1998;16 (4): 337-47.

14.King L, Williams T. Goal orientation and performance in martial arts. Journal of Sport Behaviour. 1997;20(4): 397412.

15.Gómez-López M, Granero-Gallegos A, Abraldes A, Rodríguez-Suárez N. Analysis of Self-Determined Motivation in Basketball Players through Goal Orientations. Collegium Antropologicum. 2013;37(3): 707-15.

16.Vertonghen J, Theeboom M, Pieter W. Mediating factors in martial arts and combat sports: An analysis of the type of martial art, characteristics, and social background of young participants. Perceptual \& Motor Skills: Exercise \& Sport. 2014;118(1): 41-61. 
17.Vertonghen J, Theeboom M. The social-psychological outcomes of martial arts practise among youth: a review. Journal of Sports Science and Medicine. 2010;9(4): 528-37.

18. Vertonghen J, Theeboom M. Martial arts and youth: an analysis of contextual factors. International Journal of Adolescence and Youth. 2012;17(4): 237-41.

19.Salinero Martín J, Ruiz Tendero G, Sánchez Bañuelos F. Goal orientation and motivational climate, achievement motivation, success atribution and enjoyment in an individual sport. Ciencias Aplicadas a la Actividad Física y el Deporte. 2006;83(1): 5-11.

20.Lochbaum M, Kazak Cetinkalp Z, Graham K, Wright T, Zazo R., Task and ego goal orientations in competitive sport: A quantitative review of the literature from 1989 to 2016. Kinesiology. 2016;48: 3-29.

21.Lochbaum M, Zazo R, Kazak Cetinkalp Z, Graham K, Wright T, Konttinen N. A meta-analytic review of achievement goal orientation correlates in competitive sport: A follow-up to Lochum et al. Kinesiology. 2016;48: 159-73.

22.Harwood C. Assessing Achievement Goals in Sport: Caveats for Consultants and a Case for Contextualization. Journal of Applied Sport Psychology. 2002; 14(2): 106-19.

23.Harwood C, Cumming J, Hall C. Imagery use in elite youth sport participants: reinforcing the applied significance of achievement goal theory. Research Quarterly for Exercise and Sport. 2003;74(3): 292-300.

24.Roberts G, Treasure D, Kavussanu M. Orthogonality of achievement goals and its relationship to beliefs about success and satisfaction in sport. The Sport Psychologist. 1996;10 (4), 398-408.

25.Zizzi S, Keeler L, Watson J. The interaction of goal orientation and stage of change on exercise behavior in college students. Journal of Sport Behavior. 2006;29(1): 96-110.

\section{Information about the authors:}

Cynarski W.J.; http://orcid.org/0000-0003-1252-5456; ela_cyn@ wp.pl; Department of Physical Education, University of Rzeszów; Towarnickiego 3b, 35-010 Rzeszów, Poland.

Pawelec P. (Corresponding author); http://orcid.org/0000-0003-1658-6133; przemyslaw.pawelec@idokan.pl; International Martial Arts and Combat Sports Scientific Society (IMACSSS); Towarnickiego 3b, 35-010 Rzeszów, Poland.

Yu J.-H.; http://orcid.org/0000-0003-4780-3524; jonghoon_yu@yahoo.com; Department of Health and Physical Education, Glenville State College; 200 High Street Glenville, West Virginia 26351, United States of America.

Slopecki J.; http://orcid.org/0000-0002-8980-3218; slopecki_jan@onet.eu; International Martial Arts and Combat Sports Scientific Society (IMACSSS); Towarnickiego 3b, 35-010 Rzeszów, Poland.

Bielec G.; http://orcid.org/0000-0002-4304-8931; bielec71@gmail.com; Department of Physical Education, University of Rzeszów; Towarnickiego 3b, 35-959 Rzeszów, Poland.

Kubala K.; http://orcid.org/0000-0002-8290-1624; kubala@ur. edu.pl: Department of Physical Education, University of Rzeszów; Towarnickiego 3b, 35-959 Rzeszów, Poland.

Cite this article as: Cynarski WJ, Pawelec P, Yu J-H, Slopecki J, Bielec G, Kubala K. Young people practicing martial arts and their perception of success. Pedagogics, psychology, medical-biological problems of physical training and sports, 2018;22(5):231236. doi:10.15561/18189172.2018.0502

The electronic version of this article is the complete one and can be found online at: http://www.sportpedagogy.org.ua/index.php/PPS/issue/archive

This is an Open Access article distributed under the terms of the Creative Commons Attribution License, which permits unrestricted use, distribution, and reproduction in any medium, provided the original work is properly cited (http://creativecommons.org/licenses/by/4.0/deed.en).

Received: 18.08 .2018

Accepted: 03.09.2018; Published: 30.09.2018 